\section{MS39 P01}

A natural $\mathrm{C}_{21} \mathrm{H}_{26} \mathrm{O}_{6}$ bicyclo-octenone disordered modulated structure. Nicolas Guiblin ${ }^{\mathrm{a}}$, Kurt Schenk, Lukás Palatinus ${ }^{\mathrm{a}}$, Andrew Marston ${ }^{\mathrm{b}}$, Gervais Chapuis ${ }^{\mathrm{a}}$. ${ }^{a}$ Laboratoire de Cristallographie, EPFL, CH-1015 Lausanne, Switzerland. ${ }^{b}$ Laboratoire de pharmacognosie et phytochimie, Université de Genève, CH-1211 Geneva, Switzerland. E-mail: nicolas.guiblin@epfl.ch

Keywords: organic materials obtained from plants, modulated crystals, single-crystal structure determination

The modulated structure of the natural compound, 6benzo[1,3]dioxol-5-yl-4-hydroxy-3,5-dimethoxy-7methyl-1-propyl-bicyclo[3.2.1] oct-2-en-8-one, is presented.

Data collection was performed on a single crystal, at room temperature, on a Stoe I image plate diffractometer.

The average structure is triclinic, space group $\mathrm{P} 1$, with cell parameters $\mathrm{a}=6.718(4) \mathrm{A}, \mathrm{b}=12.049(7) \mathrm{A}, \mathrm{c}=12.638(7)$ Á, $\alpha=107.10(5)^{\circ}, \beta=105.25(5)^{\circ}$ and $\gamma=89.96(6)^{\circ}$. Two independent molecules in the asymmetric unit were used. The modulation, associated with the q-vector $(0.4993(8)$, $0.500(1), 0.250(1)$ ), was found using the charge flipping method [1].

We used the program JANA2000 [2] to refine the average and the modulated structure.

The refinement was performed using a riding model for hydrogen atoms. Atomic displacement parameters (ADP) were also restrained, with a value of 1.2 times the neighbour atom. All the atoms present a displacive modulation. The propyl group attached to the bicycle presents two alternative positions, which is observed in the average structure by huge ADP values. This was refined using occupational modulation.

[1] Oszlanyi G., Sütő A. (2004): Ab initio structure solution by charge flipping, Acta Cryst. A60, 134-141; Oszlanyi G., Sütő A. (2005): Ab initio structure solution by charge flipping. II. Use of weak reflections, Acta Cryst. A61, 147-152.

[2] Petříček, V., Dušek, M., Palatinus, L. JANA2000. The crystallographic computing system (2003). Institute of Physics, Praha, Czech Republic.

\section{MS39 P02}

Single crystal $x$-ray study of $\mathrm{Ba}_{2} \mathrm{Cu}_{2} \mathrm{Te}_{4} \mathrm{O}_{11} \mathrm{Br}_{2}$ and its incommensurate modulated superstructure companion $\mathbf{B a}_{2} \mathbf{C u}_{2} \mathbf{T e}_{4} \mathbf{O}_{11+\delta} \mathbf{B r}_{2}$ Rie Takagi, Mats Johnsson and Sven Lidin

Inorganic Chemistry, Stockholm University, SE-106 91 Stockholm, Sweden. E-mail: takagi@inorg.su.se

\section{Keywords: incommensurate, superstructure,} modulation

Compounds containing lone pair elements, such as Te, are very interesting from the structural point of view, as the lone pair non-bonding regions create low dimensional geometrical arrangements. We synthesized the two new compounds $\mathrm{Ba}_{2} \mathrm{Cu}_{2} \mathrm{Te}_{4} \mathrm{O}_{11} \mathrm{Br}_{2}$ (I) and $\mathrm{Ba}_{2} \mathrm{Cu}_{2} \mathrm{Te}_{4} \mathrm{O}_{11.237} \mathrm{Br}_{2}$ (II) as members of the AE-Cu-Te-O-X (AE=alkaline earth, $\mathrm{X}=$ halide ) family of compounds via transport reactions. Preliminary single crystal X-ray analysis indicates that compound $\mathbf{I}$ crystallizes in the orthorhombic system, but attempts at refinement proved unsatisfactory. A closer inspection of the reciprocal lattice reveals systematic, non-crystallographic absences that indicate twinning. The structure is in fact triclinic (S.G. C-1, equivalent to $\mathrm{P}-1$ ), with the unit cell parameters (at 120K) $\mathrm{a}=10.9023(6), \mathrm{b}=15.0824(8), \mathrm{c}=9.3810(5), \alpha=89.662(4)$, $\beta=106.895(4), \gamma=89.992(4)$. It is layered and built from $\left[\mathrm{TeO}_{3} \mathrm{E}\right]$ tetrahedra, $\left[\mathrm{TeO}_{3+1} \mathrm{E}\right]$ trigonal bipyramids $(\mathrm{E}$ being the lone pair of $\left.\mathrm{Te}^{\mathrm{IV}}\right),\left[\mathrm{CuO}_{4}\right]$ squares and irregular $\left[\mathrm{BaO}_{10} \mathrm{Br}\right]$ polyhedra. The crystal structure of II shows the same basic structure as I, but with partial occupancy on one $\mathrm{O}$ site. The presence of satellites reveals that ordering of these $\mathrm{O}$ partial vacancies creates an incommensurate modulation for $\mathrm{Br}$ and $\mathrm{Te}$. The modulated structure of II was solved in the triclinic super space group $\mathrm{X}-1(\alpha \beta \gamma) 0$, with the $\mathrm{q}$ vector $\approx 1 / 16 \mathbf{c}^{*}$.

[1] C.R. Feger and J. W. Kolis, Inorg. Chem., 37 (1998) 40464051.

[2] J. Galy, G. Meunier, S. Andersson, and A. Åström, J. Solid State Chem., 13 (1975) 142.

\section{MS39 P03}

Incommensurate phases in ternary solid solutions $\mathrm{P}$. J. Bereciartua $^{\mathrm{a}}$, T. Breczewski ${ }^{\mathrm{b}}$, F. J. Zuñiga ${ }^{\mathrm{a}}$, ${ }^{\mathrm{a}}$ Dept. of Condensed Matter Physics, ${ }^{b}$ Dept. of Applied Physics II, University of the Basque Country, Bilbao, Spain. E-mail: wmbbepep@ehu.es

Keywords: incommensurate structures, solid solutions, modulated crystal structures

In the ternary system $\operatorname{In}_{2} \mathrm{O}_{3}: \mathrm{TiO}_{2}: \mathrm{A}_{2} \mathrm{O}_{3}$ and $\mathrm{In}_{2} \mathrm{O}_{3}: \mathrm{TiO}_{2}: \mathrm{BO}$, with $\mathrm{A}: \mathrm{Al}, \mathrm{Cr}, \mathrm{Mn}, \mathrm{Fe}, \mathrm{Ga}$ and $\mathrm{B}: \mathrm{Mg}$, $\mathrm{Mn}, \mathrm{Co}, \mathrm{Ni}, \mathrm{Cu}, \mathrm{Zn}$, there exist some solid solutions within certain range. They are monoclinic or orthorhombic incommensurate phases depending on the temperature and the composition [1]. The present work has studied the structure of the monoclinic one in the system $\operatorname{InAl}_{1}$ ${ }_{x} \mathrm{Ti}_{\mathrm{x}} \mathrm{O}_{3+\mathrm{x} / 2}(\mathrm{x}=2 / 3)$. It consists on $\mathrm{InO}_{6}$ octahedral layers which alternate along $\vec{c}$ with $\mathrm{M}-\mathrm{O}$ planes $(\mathrm{M}=\mathrm{Al}, \mathrm{Ti})$. These $M$ atoms share the same position with complementary occupation, whereas the sites of $\mathrm{O}$ atoms of this plane (O2) are partially occupied.

The parameters of the unit cell are $\mathrm{a}=5.857(4) \AA$, $b=3.361(3) \AA, c=6.355(5) \AA$ and $\beta=107.96(5)^{\circ}$, and the modulation wavevector is parallel to the monoclinic axis $\vec{q}=0.3503(5) \vec{b}^{*}$. The systematic extinctions and the structure refinement point out that superspace group is $C 2 / m\left(0 \sigma_{2} 0\right) s 0$.

A modulated structure model has been proposed in which the atoms of the octahedral layers modulate their positions and the $\mathrm{M}$ atoms modulate also their occupation complementary. Besides, the atomic domain of $\mathrm{O} 2$ can be represented by a sawtooth function combined with several orthogonal harmonic functions.

On the other hand, a composite model has been checked. It includes two subsystems. One of them is formed by the octahedrals layers and the $\mathrm{M}$ atoms, while the $\mathrm{O} 2$ atoms make up the other one, as in the model proposed for the $\mathrm{InCr}_{1-\mathrm{x}} \mathrm{Ti}_{\mathrm{x}} \mathrm{O}_{3+\mathrm{x} / 2} \quad(\mathrm{x}=2 / 3) \quad$ system [2]. However, unlike in this model, the atomic domanin of the $\mathrm{O} 2$ is discontinuous, described as in the modulated model. The equivalence between both models is shown.

[1] Brown F., Kimizuka N., et al., J. Solid State Chem., 1999, $147,438$.

[2] Michiue Y., Onoda M., et al., J. Solid State Chem., 2004, 177, 2644 . 